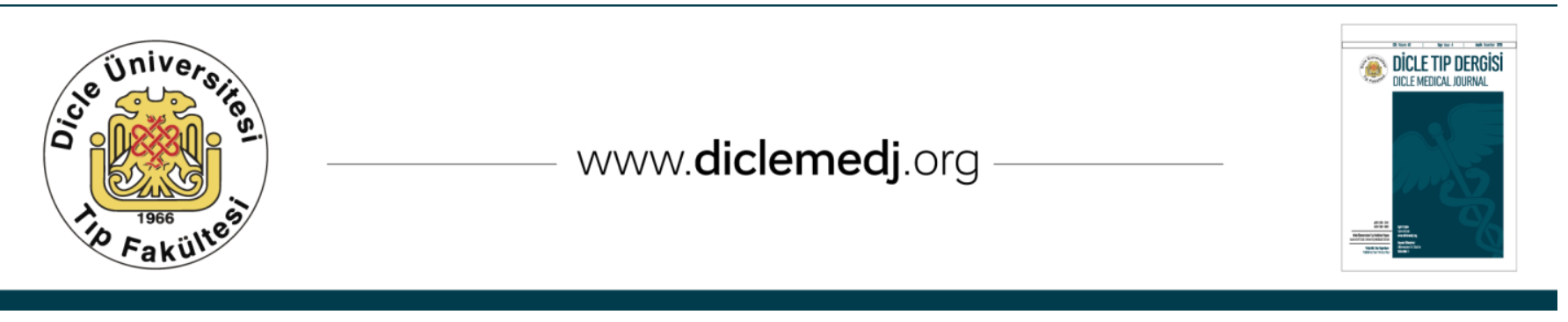

Olgu Sunumu / Case Report

\title{
Olanzapine Bağlı Obsesif-Kompülsif Semptomlar Oluşan Bir Capgras Sendromu Olgusu
}

\author{
Betül Uyar Ekmen ${ }^{1}$ \\ 1 Diyarbakır Selahaddin Eyyubi Devlet Hastanesi Ruh Sağlığı ve Hastalıkları AB. Diyarbakır, Türkiye ORCID: 0000-0002-6428-1097
}

Geliş: 11.09.2018; Revizyon: 05.02.2019; Kabul Tarihi: 04.03.2019

$\ddot{0} \mathbf{z}$

Capgras sendromu, kişinin kendisine yakın olan diğer kişilerin, nesnelerin, kendisinin tıpatıp benzerleri ile değiştirildikleri biçiminde sanrısal bir inanıştır. Bu sendrom daha çok şizofreni kavramı içinde yer alır. Capgras sendromunun tedavisi; altta yatan bozukluğun tedavisidir. Klozapin, risperidon, olanzapin ve ketiapin gibi tedavi için kullanılan atipik antipsikotikler hastalarda obsesif kompülsif semptomlar meydana getirebilirler. Bu durumda hastanın psikotik belirtileri mevcut tedaviden fayda görüyorsa mevcut antipsikotik tedavi kesilmez. Bunun yerine serotonin geri-alım inhibitörü ya da klomipramin gibi obsesif kompülsif belirtiler için etkili başka bir grup ilaç eklenebilir.

$\mathrm{Bu}$ yazıda olanzapin tedavisinden fayda gören Capgras sendromu bulunan, şizofreni tanısı konmuş bir hastadan bahsedilmiştir. Olanzapin tedavisi, hastada obsesif kompülsif semptomlar meydana getirmiştir. Obsesif kompülsif belirtiler, Yale-Brown Obsesyon Kompulsiyon Derecelendirme Ölçeği ile değerlendirilmiştir. Hasta olanzapinden fayda gördüğü için olanzapin kesilmemiştir. Bunun yerine tedaviye fluoksetin eklenmiştir. Hastanın obsesif kompülsif belirtileri tedaviye fluoksetin eklenmesiyle azalmıştır.

Anahtar kelimeler: Capgras sendromu, olanzapin, fluoksetin, obsesif-kompülsif semptomlar.

DOI: 10.5798/dicletip.539908

Yazışma Adresi / Correspondence: Betül Uyar Ekmen, Dicle Üniversitesi Lojmanları 4. Sk No: 6721280 Sur Diyarbakır, Türkiye e_mail: betuluyar@hotmail.com 


\title{
A Capgras Syndrome Case With Obsessive-Compulsive Symptoms Associated With Olanzapine
}

\begin{abstract}
Capgras syndrome is a delusional belief that other people close to oneself, objects, are replaced with exactly the same ones. This syndrome is rarely seen and is included in the concept of schizophrenia. Treatment of Capgras syndrome is the treatment of the underlying psychiatric disorder. The atypical antipsychotics that are used to treat this syndrome such as risperidone, clozapine olanzapine, and quetiapine may cause obsessive-compulsive symptoms in patients. As it is, the patient's psychotic symptoms benefit from the present treatment, drugs those are effective for the obsessivecompulsive symptoms such as serotonin reuptake inhibitors, or clomipramine may be added to undergoing treatment, rather than existing antipsychotic treatment discontinuation. In this article, we mentioned of a schizophrenic patient with Capgras syndrome who profited from olanzapine treatment.

The drug created obsessive-compulsive symptoms in the patient. The obsessive compulsive symptoms were evaluated with Yale-brown obsessive compulsive scale (Y-BOCS). Olanzapine treatment is continued as she benefited from the treatment. To overcome these symptoms, fluoxetine added to the treatment. Patient's symptoms decreased with the addition of fluoxetine.
\end{abstract}

Keywords: Capgras syndrome, olanzapine, fluoxetine, obsessive-compulsive symptoms.

\section{GİRIŞ}

Capgras sendromu, kişinin kendisine yakın olan diğer kişilerin, nesnelerin, kendisinin tıpatıp benzerleri ile değiştirildikleri biçiminde sanrısal bir inanıştır. İlk olarak, 1923'te Fransız psikiyatrist Jean Marie Joseph Capgras ve Reboul-Lachaux tarafından tanımlanmıștır ${ }^{1}$. Bu sendrom daha çok şizofreni kavramı içinde yer alır2,3. Literatürde Capgras Sendromunun tedavisine dair sinırlı miktarda veri bulunmaktadır. Öncelikle genel tıbbi duruma ait bir patoloji varlığı mutlaka araştırılmalıdır. $\mathrm{Bu}$ durum dışlandıktan sonra temeldeki psikiyatrik bozukluğa yönelik tedavi yapılmalıdır ${ }^{4}$. Psikoz tedavisinde kullanılan antipsikotiklerden klozapin ${ }^{5}$, risperidon ${ }^{6}$, ketiapin $^{7}$ ve olanzapin ${ }^{8-10}$ ile obsesif kompülsif semptomların ortaya çıktığı veya olan semptomların ağırlaştığı, çeşitli olgularda bildirilmiştir. $\mathrm{Bu}$ yazıda, olanzapin tedavisi sırasında obsesif kompülsif semptomları ortaya çıkan Capgras sendromu tanısı konmuş bir olgudan bahsedilmiștir. Yale-Brown Obsesyon Kompülsiyon Derecelendirme Ölçeği (Y-BOCS); obsesif kompulsif rahatsızlı̆̆ bulunan hastalarda görülen belirtilerin tipini ve ciddiyetini değerlendirmek maksadiyla düzenlenmiştir. Y-BOCS, 0 ila 4 arasında puanlanabilen, 5 madde obsesyon, 5 madde kompülsiyon olmak üzere toplam 10 maddenin değerlendirilmesi ve skorlanması esasına dayanır. Böylece, obsesyonlar 20 ve kompülsiyonlar 20 olmak suretiyle en fazla 40 puan üzerinden derecelendirme yapılır ${ }^{11}$. Ölçeğin Türkçe geçerlilik güvenilirlik çalışması yapılmıştır ${ }^{12}$.

\section{OLGU}

35 yaşında kadın hasta, bekar, lise mezunu, çalışmıyor. Hastanın polikliniğe ilk getirilişinde kötülük görme hezeyanları, beynine çip yerleştirildiği ve düşüncelerinin okunduğuna dair düşünceleri mevcuttu. Anne, baba ve ablasının gerçek ailesi olmadığına, başka kişilerin onların yerine geçtiğine inanıyordu.

Hastanın özgeçmişinden, 6 yıldır belirtilerinin olduğu, ancak tedaviye 2 yıl önce başlandığı öğrenildi. Hiç hastaneye yatış öyküsü yoktu. Olanzapin tedavisi (10 mg/gün) ile kısmi remisyona giren hastanın psikotik belirtilerinde, son 3 aydır ilaç kullanmadığı için artış olmuştu. 
Hastanın soygeçmişine bakıldığında, 51 yaşındaki ablasında negatif belirtilerin baskın olduğu şizofreni rahatsızlığ olduğu ve olanzapin tedavisi (15 mg/gün ) ile kısmi remisyonda olduğu öğrenildi.

Yapılan ruhsal durum muayenesinde; yaşında gösteren hastanın özbakımı azalmıştı. Duygudurum künt, duygulanım duygudurum ile uyumluydu. Spontan konuşma ve psikomotor aktivite azalmıştı. Düşünce hızı azalmıştı ve düşünce blokları mevcuttu. Kötülük görme hezeyanları, anne, baba ve ablasının gerçek ailesi olmadığına, başka kişilerin onların yerine geçtiğine inanma şeklinde hezeyanları vardı. Beynine çip yerleştirildiğine ve düşüncelerinin okunduğuna dair hezeyanları mevcuttu.

Hastanın organik tetkikleri (hemogram, tam biyokimya, B12, folat ve tiroid fonksiyon testleri) normaldi.

Mevcut bulgularla hastaya şizofreni tanısı konuldu. Hastanin tablosuna Capgras sendromunun eşlik ettiği düşünüldü. Olanzapin tedavisine $10 \mathrm{mg}$ /gün dozunda başlandı. Bir ay sonraki kontrolünde, psikotik belirtileri azalmıștı. Olanzapin, $15 \mathrm{mg} /$ gün dozuna yükseltildi. İkinci kontrolünde, hastanın psikotik belirtileri daha da azalmakla beraber, devam ediyordu. Olanzapin dozu günde 20 mg'a yükseltildi. Üçüncü kontrolünde, hastanın psikotik belirtileri ve Capgras Sendromu belirtileri kendini rahatsiz etmeyecek düzeydeydi. Ancak, hastada içinden sürekli şarkı söyleme, şarkıların doğru söylenildiği konusunda şüpheye düşme, perde, halı deseni gibi nesnelere dikkat kesilip hatalarını bulmaya çalışma ve sayma belirtileri başlamıştı. Bu davranışlar, kendisine saçma geliyor ancak bunlara engel olamıordu. Bu belirtiler, günde 1 saatten fazla vaktini alıyor, günlük yaşam aktivitelerini etkiliyor ve hayatını güçleştiriyordu. $\mathrm{Bu}$ görüşmede hastanın obsesyon skoru 12 olarak, kompülsiyon skoru ise 15 olarak değerlendirildi. Obsesif kompülsif belirtilerin olanzapine bağlı gelişmiş olabileceği düşünüldü. Olanzapin tedavisine, $20 \mathrm{mg} /$ gün dozunda devam edilip, tedaviye $20 \mathrm{mg}$ /gün dozunda fluoksetin eklendi. Dördüncü kontrolünde, hastanın psikotik belirtileri kısmen remisyondaydı. Hastanın, obsesif kompülsif belirtileri azalmıştı ve kendisini rahatsız etmeyecek düzeydeydi. Bu görüşmede hastanın obsesyon skoru 5'e, kompülsiyon skoru ise 7'ye düşmüștü.

\section{TARTIŞMA}

Hastamızın daha önceden şizofreni tanısı mevcuttu. Üstüne, ailesinin değiştirildiğine dair hezeyanları da eklenince Capgras sendomu da eşlik eden şizofreni tanısı düşünüldü. Capgras sendromunun, genellikle şizofreni ve organik psikozla birlikte görüldüğü bilinmektedir ${ }^{2}$. Capgras sendomunun tedavisi; altta yatan psikiyatrik bozukluğun tedavisidir ${ }^{4}$. Hastamız, daha önce olanzapin tedavisinden fayda görmüștü ve soygeçmişinde olanzapin tedavisinden fayda gören şizofreni tanılı ablasının olduğu öğrenilmişti. Bu yüzden, hastaya tekrar olanzapin tedavisi başlanmıştır. Hasta, olanzapinden fayda görmüș, ancak olanzapin hastada obsesif kompülsif semptomları tetiklemiştir. Literatürde bu konu ile alakalı çalışmalar mevcuttur ${ }^{8-10}$ Olanzapinden fayda gördüğü için, olanzapin kesilmemiş ve tedaviye fluoksetin eklenmiştir. Tedaviye fluoksetin eklenmesi ile, hastanın obsesif kompülsif semptomlarında Y-BOCS ile belirlenen makul bir iyileşme olmuştur. Mottard ve arkadaşlarının bildirdikleri 2 olguda, olanzapin ile obsesif kompülsif belirtiler ortaya çıkmıştır. Ancak hastaların psikotik belirtileri olanzapin ile yatıştığ için olanzapin kesilmemiştir. Bunun yerine, tedavi protokolüne, bir olguda fluoksetin, bir diğerinde ise klomipramin eklenmiştir. Hastalar, bu tedavilerden fayda görmüștür ${ }^{10}$.

Sonuç olarak, Capgras sendromu altta yatan psikiyatrik bozukluğun tedavisi ile remisyona 
giren yanlıș tanıma bozukluklarından biridir. Tedavide kullanılan atipik antipsikotiklerle obsesif kompülsif semptomlar ortaya çıkabilir. Hastanın psikotik belirtileri mevcut tedaviden fayda görüyorsa, antipsikotik tedaviyi kesmek yerine devam ettirip, serotonin gerialım inhibitörü veya klomipramin gibi obsesif kompülsif semptomlar için etkili başka bir grup ilaç eklemek alternatif bir yaklaşım olabilir.

Çıkar Çatışması Beyanı: Yazarlar çıkar çatışması olmadığını bildirmişlerdir.

Finansal Destek: Bu çalışma her hangi bir fon tarafından desteklenmemiştir.

Declaration of ConflictingInterests: The authors declare that they have no conflict of interest.

Financial Disclosure: No financial support was received.

\section{KAYNAKLAR}

1. Berson RJ. Capgras' syndrome. Am Jour Psy, 1983; 140: 969-78.

2. Sinkman A. The syndrome of Capgras. Psychiatry: Interpersonal and Biological Processes. 2008; 71.4: 371-8.

3. Tamam L, Karatas G, Zeren T, et al. The prevalence of Capgras syndrome in a university hospital setting. Acta Neuropsychiatrica, 2003; 15.5: 290-5.
4. Enoch D, Ball H: Az Rastlanır Psikiyatrik Sendromlar. 1. Baskı, Okyanus Yayın, İstanbul, 2002, s.15-34.

5. Leung JG, Palmer BA. Psychosis or obsessions? Clozapine associated with worsening obsessivecompulsive symptoms. Case reports in psychiatry. 2016.

6. Andrade C. Risperidone may worsen fluoxetine-treated OCD. J Clin Psychiatry. 1998; 59: 255-6.

7. Khullar A, Chue P, Tibbo P. Quetiapine and obsessivecompulsive symptoms (OCS): case report and review of atypical antipsychotic-induced OCS. Journal of Psychiatry and Neuroscience. 2001; 26.1: 55.

8. Morrison D, Clark D, Goldfarb E, et all. Worsening of obsessive-compulsive symptoms following treatment with olanzapine [letter]. Am J Psychiatry. 1998; 155: 855.

9. Al-Mulhim A, Atwal S, Coupland N. Provocation of obsessivecompulsive behaviour and tremor by olanzapine [letter]. Can J Psychiatry. 1998; 43: 645.

10. Mottard D, La Sablonniere JF. Olanzapine induced obsessivecompulsive disorder. Am J Psychiatry. 1999; 156: 799-800

11. Goodman WK, Price LH, Rasmussen SA, ve ark. Yalebrown obsessive compulsive scale (Y-BOCS). Arch gen psychiatry. 1989; 46: 1006-11.

12. Tek C, Uluğ B, Rezaki BG ve ark. Yale-Brown Obsessive Compulsive Scale and US National Institute of Mental Health Global Obsessive Compulsive Scale in Turkish: reliability and validity. Acta Psychiatrica Scandinavica. 1995; 91.6: 410-3. 